\title{
Water consumption pattern and conservation measures in academic building: a case study of Jamshoro Pakistan
}

\author{
Bushra Danish Talpur ${ }^{1} \cdot$ Asmat Ullah $^{3,4} \cdot$ Shoaib Ahmed $^{2}$
}

Received: 18 April 2020 / Accepted: 24 September 2020 / Published online: 7 October 2020

(c) Springer Nature Switzerland AG 2020

\begin{abstract}
The building construction industry contribute substantially toward the exhaustion of most of the natural resources and water is one of them. Unsustainable water uses in buildings during its operation phase augmenting water resources consumption and degradation. To reduce resource consumption and harmful environmental impacts; green buildings construction is being promoted. Water conservation is one of the important components in the design of green buildings to save freshwater and satisfy the increasing demand for water. United States (U.S.) green building reference guide rating system contains 11 points out of 110 points for water efficiency for building design and construction. Considering these facts, this study aims to analyze water consumption and conservation potential in the Center for advanced studies during operational phase in the city Jamshoro. Water consumption by occupants during working hours has been assessed. Two scenarios were developed to assess and calculate water use in existing infrastructure and then compared with criteria provided by Leadership in Energy and Environmental Design (LEED) guidelines for new construction and design. It has been observed that currently no proper provision is provided for water reuse or recycling and ordinary water consumption fixtures are used. Results show that $33.50 \%$ of total consumed water can be saved by using LEED design and construction criteria. Moreover, grey water reuse can also reduce freshwater consumption $42-25 \%$ in both scenarios. Grey water reuse and reducing indoor water consumption in the building can help to conserve water. Such water usage systems will not only help to reduce energy cost but also contribute positively toward ensuring future availability of resources and improve environmental performance.
\end{abstract}

Keywords Building operation · Water conservation · Water efficient techniques · Green building · Environmental performance

$\begin{array}{ll}\text { List of symbols } \\ W_{\text {wcsf }} & \text { Water consumption water closets single flush } \\ C_{f} & \text { Capacity per flush } \\ t_{n} & \text { Number of times used } \\ O_{n} & \text { Number of occupants } \\ D_{n} & \text { Number of days per week/month } \\ W C S F_{n} & \text { Total number of water closet } \\ W_{\text {wcdf }} & \text { Water consumption water closets single flush } \\ W C D F_{n} & \text { Total number of water closet }\end{array}$

$W_{u} \quad$ Water consumption from urinal

$U_{n} \quad$ Total number of urinals

$W_{b s} \quad$ Water consumption from bidet spray

$\mathrm{Q} \quad$ Flow rate (gallons per $15 \mathrm{~s}$ )

$B S_{n} \quad$ Total number of bidet spray

$W_{\text {If }} \quad$ Water consumption from lavatory faucet

$L F_{n} \quad$ Total number of lavatory faucet

$W_{k f} \quad$ Water consumption from kitchen faucet

$K F_{n} \quad$ Total number of kitchen faucet

$\triangle$ Bushra Danish Talpur, bushra.d.talpur@gmail.com | 'Department of Architecture and Planning, Dawood University of Engineering and Technology, Karachi, Sindh, Pakistan. ${ }^{2}$ Department of Chemical Engineering, Dawood University of Engineering and Technology, Karachi, Sindh, Pakistan. ${ }^{3}$ US. - Pakistan Center for Advanced Studies in Water (USPCASW), Mehran University of Engineering and Technology (MUET), Jamshoro, Sindh, Pakistan. ${ }^{4}$ The Joint Graduate School of Energy and Environment (JGSEE), King Mongkut's University of Technology Thonburi (KMUTT), Bangkok 10140, Thailand. 


\section{Introduction}

Fresh water availability and wastewater discharge are serious concerns of urban dwellers around the globe but some communities of specific countries including Pakistan are more vulnerable. The level of vulnerability of people varies depending on the water resources endowments, the place of living as well as their direct or indirect exposure to the discharged wastewater. Hydrological cycle and thus water resources are already being affected by the climate change [1]. In Pakistan, per capita water availability has declined from 2172 to $1014 \mathrm{~m}^{3}$ by the year 2016, labelling Pakistan as the highwater stress country. Population growth and climate change are the main stressors toward water security in the country. In Pakistan $96 \%$ of water is consumed by agriculture, remaining $4 \%$ is used for industrial, domestic and other purposes [2], therefore water insecurity will ultimately cause food insecurity. Traditional water resources management practices at local, provincial, and even country level are contributing toward water quality degradation.

A considerable attention has been paid toward agricultural intensification to address future food insecurity but nothing significant has been done so far to increase water use efficiency in this sector. Consequently, withdrawing water from agriculture and supplying it to urban settlements is difficult that is why access to fresh water for population in Pakistan is comparatively low [3]. In Pakistan per capita water consumption varies from $30 \mathrm{~L}$ per capita per day to $350 \mathrm{~L}$ per capita per day, depending on regions like upstream population consume more and the availability for population living in downstream people is less [1]. Water consumption pattern also varies within domestic sector. Poor are facing problems to have access to fresh water and fetching water from far areas is common. Most of the time water quantity as well quality is compromised for under privileged inhabitants of the society. Nevertheless, it is surprising to know that a non-serious water consumption behavior in urban buildings is still in practice [4]. More specifically, consumers of public sector buildings are not rationally using fresh water, knowingly that Pakistan is currently facing water crises.

Better understanding of the pattern of municipal water usage is necessary to overcome the gap of demand and supply of water [5]. Water demand is putting lot of pressure on groundwater resources as well. Water conservation is vital and it is the only way to address scarcity of water which is a serious threat to Pakistan [1]. Effective approaches are required to promote public awareness regarding the need to involve in water conservation move at all levels [6]. If efficient use and conservation of water will not be adopted then society will face tremendous problems in the coming years [7].

\subsection{Challenges towards urban water supply}

Water shortage is not the only problem, but wasteful use of water is also critical issues since it contributes toward indirect energy waste which is required to supply that water and thus contribute toward global warming. In Pakistan water use practices are not in union with conservation of water [1]. To cope with this situation, sustainable development techniques need to be adopted to conserve water resources and manage wastewater sustainably. Urban water systems contribute substantially toward water consumption as well as freshwater resources degradation through mismanaged water supply and sanitation systems $[2,8]$. Analysis of wastage of water is also challenging as the amount of miss use along with leakages [9].

Though wastewater can be treated through water treatment technologies prior to getting discharged into the water system, but instead of treating wastewater, adopting water saving technologies are more effective and economical approach to conserving water. Water conservation will not only help to improve the environmental and social well-being of the society but it will also indirectly contribute toward energy conservation [10]. This aims to put emphasis on an increasing water conservation techniques and sustainable building construction through sustainable innovations and green buildings [11].

To this end U.S. Green Building Council (USGBC) has been established to promote environment-friendly construction and design [12]. From 2003 Leadership in Energy and Environmental Design (LEED) is working on certification of buildings based on six building components. Water is one among other six components, which encourages efficient water use in the building [13] through efficient fixture. These efficient fixtures help in reduction of indoor potable water consumption in buildings [14]. In year 2000, the sustainable use of water was focused in Millennium Development Goals (MDGs) of the United Nations Development Program (UNDP) [15] and this legacy has been continued in the Sustainable Development Goals (SDGs) [16]. Different studies have been conducted on water saving approaches and techniques and to encourage sustainability the sane use of water is influential tool in public buildings including university campuses [17]. 


\subsection{Water conservation need and existing literature}

Worldwide several studies have been carried out regarding reduction of water consumption in buildings [18-22]. Residential water consumption and water reuse have also been a well-focused research area of [19]. A detailed study have been conducted in USA on water consumption in institutional and commercial buildings by [23]. A similar study have been carried out in Brazil to analyze behavioral water consumption in institutional buildings [24]. LC Proença and E Ghisi (2010) [19] Conducted study in 10 office buildings, concluded that in office buildings users are not concern about water saving but there is a potential to conserve freshwater by adopting the practice of reuse of grey water and changing the behavior of users. Interestingly, in public buildings and academic institutional buildings, the wasteful consumption is a common practice since the users do not pay the development and maintenance costs [23]. Water consumption in governmental buildings of Florianopolis have been estimated through survey of users and it revealed a higher per capita consumption and therefore measure to reuse graywater have been suggested to conserve water [24]. A program was conducted in Brazilian buildings to assess the potential of water conservation the results came expressive in university campuses by implementing water conserving measures [25]. Water saving methods are becoming important in public and institutional buildings because of their high operational costs of the buildings, result of rational water consumption can pay the rest of building operational cost [25].

Study by [29] shows different strategies of water saving in schools located in Brazil and the results show that indoor water consumption can be reduced by using water saving techniques. Another study conducted by [30] and they recommended a replacing all existing fixture and installing new low cost fixtures of one of the hostels in Spain. The results indicate that $21.5 \%$ of total consumption was saved and thus average daily consumption of water per guest has been declined from 321 to $252 \mathrm{~L}$ per day. Cape Town, South Africa was in news during early 2018 because of water crises. Pakistan being a water scarce country need to address the urban water issues but unfortunately, nothing much has been done in Pakistan to encourage people to conserve water especially in the public building including university campuses. Since treating and reusing water is not a norm in Pakistan and wastewater is not considered a resource.

Inefficient plumbing fixtures replacement in the public buildings need to be encouraged to conserve water. Study conducted by [31] proves that, ordinary taps replacement with water saving taps would reduce water consumption by $26.2 \%$ and produce less environmental impacts throughout its life cycle. Nevertheless, these technologies are yet to be widely adopted in Pakistan especially in public buildings where water consumption is comparatively high [2]. Comparing different alternatives is helpful to assess the potential of fresh water in public buildings. To this end, this study aims to analyze water consumption and conservation measure of an institutional building in Pakistan and compare the indoor water consumption techniques with the criteria provided by LEED. In LEED guidelines, criteria for calculating water consumption in buildings has been provided in detail, in which separate male and female water consumption calculation measures are given as well. Water consumption patterns of male and female are not $100 \%$ same, as male use toilets and urinals whereas, female use only toilet. The study also tries to estimate the potential of water conservation through installing efficient fixtures as well as the potential of grey water reuse. The research would bring knowledge of conservation patterns in public-private sector. Thus, areas for improvement which consume maximum fresh water during working hours in the building are identified. Institutions like this educate thousands of students and make them able to live a life which is directly and indirectly beneficial not to themselves only but for the global needs as well. Careless behaviors of human being have already made this planet earth suffer in the form of climate change. Studies like this would encourage youth to step forward and eliminate the problems from the roots for betterment of their generations. By saving and reusing water in the institutes not only effect positively on their attitude towards water conservation but also develop nature to aware users regarding water saving.

\section{Methodology}

\subsection{Study area description}

Water consumption of public institutional buildings has been carried out by taking a case study, an academic building at Mehran University of Engineering and Technology Jamshoro, Pakistan occupying a gross area of $5084 \mathrm{~m}^{2}$. The selected case study building is a newly constructed academic building. It has three floors i.e. ground-, first-, and second floor but no basement. It consists of 5 classrooms, a library, 5 laboratories, administration offices, faculty offices, researcher's offices, seminar hall, conference hall, and a cafeteria. Since the building was at its completion stage at the time when this study was conducted. It was claimed that the studied building focused on the water conservation principle and fulfill the criteria of green buildings. Moreover, the first hand and authentic data was available to take this building as a case study that could 


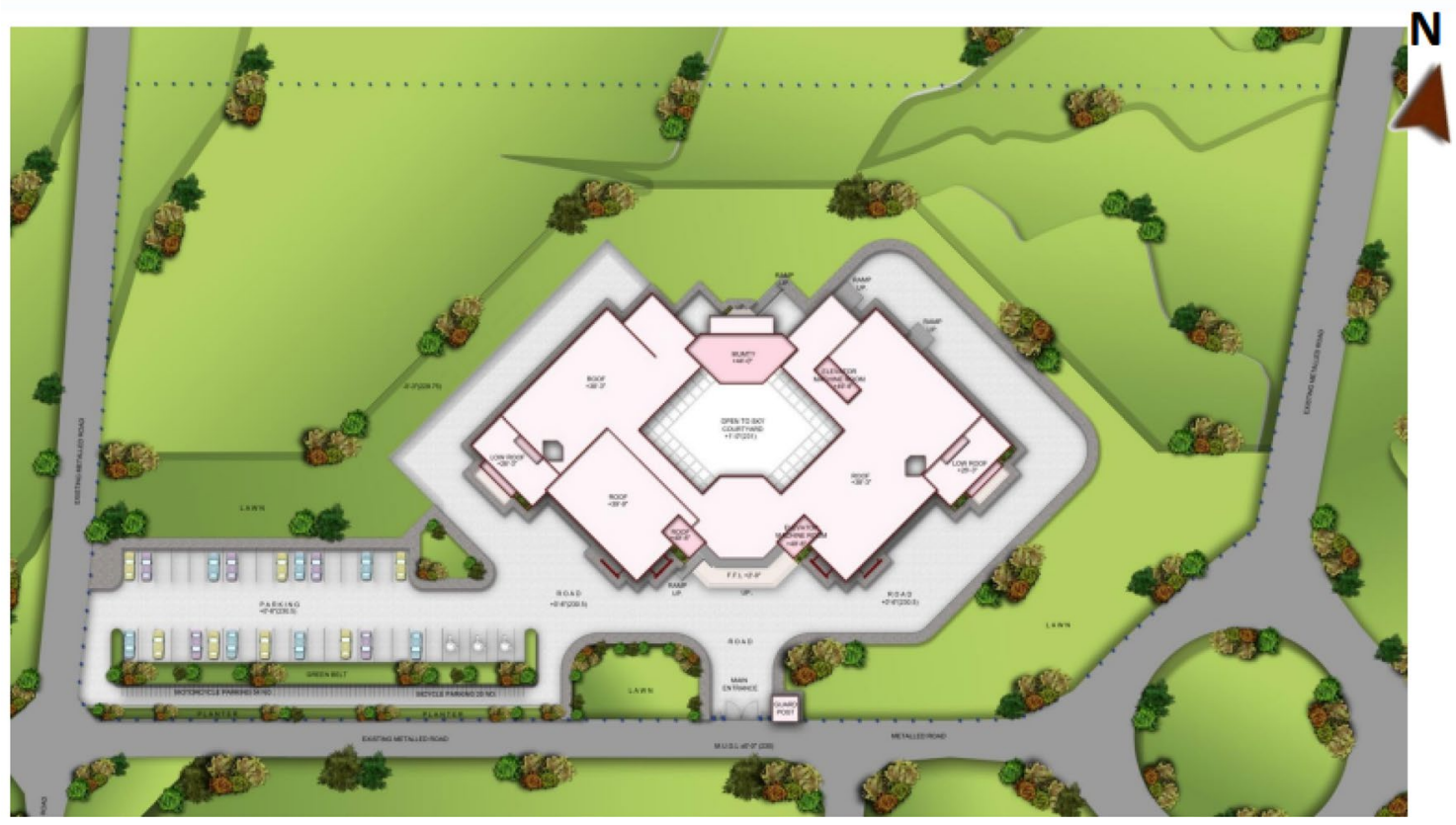

Fig. 1 Master plan of the study area

largely represent the water consumption and water conservation potential in the academic buildings of Pakistan. Master plan of the study area is shown in Fig. 1.

To achieve the objectives of this study, 2 case scenarios has been developed to analyze water consumption of the building. 1st case scenario deals with water consumption of the total existing occupants in the building based on the present condition considering total current employees and enrolled students. 2nd case scenario deals with maximum space available for the occupants inside building i.e. a future scenario. For both cases, water consumption and potential water savings by using efficient fixtures have been calculated.

At the time when study was conducted, there were 398 occupants including graduate students, staff, and faculty members. Whereas, total 630 occupant's space is provided in building design, covering all floors with respect to space division. For future scenario, when all the rooms and utilities will be occupied by occupants for different purposes, it has been assumed that the number of both male and female ratio will be equal in 2 nd case.

\subsection{Data collection and analysis}

This section describes the methodology adopted to compute water consumption inside the building considering the current number of occupants and future maximum occupancy with equal share of males and females.
Currently, conventional plumbing fixtures are installed in the building, therefore the calculations have been carried out considering two perspectives. First perspective indicate water consumption by means of conventional plumbing fixtures used in the building. The second context indicates water consumption by means of certified/ standard plumbing fixtures used in the building to assess the potential of water conservation. The list of standard plumbing fixtures is provided by LEED reference guide for green building design and construction. Obtained manufacturers product literature is compared with the standard efficient products given by U S Environmental Protection Agency (EPA) WaterSense [26]. Water use calculation is based on fixture and fitting, water consumption rates and the estimated use by the occupants. Occupants estimated use has been determined by calculating occupants and applying appropriate fixture use rates to each. Table 1 provides the total count of appliances used in the case study building and provides the per day frequency of the usage of the fixture by male and female occupants. These standard values have been used for the calculations. It has been assumed that the water consumption will not significantly vary by any handicapped occupant, therefore it has not been separately analyzed in this study. Table 1 shows the amount of water used in conventional plumbing fixtures. Provided by LEED and Environmental agency-Abu Dhabi. These measures are taken for calculations. 
Table 1 Indicates the standards of Uniform Plumbing Codes (UPC) and International Plumbing Codes (IPC) for plumbing water use fixture, standards of EPA Water Sense $[14,26]$

\begin{tabular}{|c|c|c|c|c|c|c|c|}
\hline Flush fixture & Total fixtures & Gender & $\begin{array}{l}\text { FTE (full time } \\
\text { equivalent) use/ } \\
\text { day }\end{array}$ & Units & $\begin{array}{l}\text { UCP } \\
\text { and IPC } \\
\text { standards }\end{array}$ & $\begin{array}{l}\text { U.S. EPA } \\
\text { water sense } \\
\text { standards }\end{array}$ & $\begin{array}{l}\text { Conventional } \\
\text { plumbing fixture } \\
\text { water use }\end{array}$ \\
\hline Water closet & 35 & $\begin{array}{l}\text { Male } \\
\text { Female }\end{array}$ & $\begin{array}{l}1 \\
3\end{array}$ & Gallons/flush (g/f) & 1.60 & 1.28 & 1.6 \\
\hline $\begin{array}{l}\text { Urinals (gpf) } \\
\text { Flow fixture }\end{array}$ & 08 & Male & 2 & $(g / f)$ & 1.00 & 0.50 & 1 \\
\hline $\begin{array}{l}\text { Lavatory faucet, } \\
\text { duration } 15 \mathrm{~s}\end{array}$ & 15 & $\begin{array}{l}\text { Male } \\
\text { Female }\end{array}$ & $\begin{array}{l}3 \\
3\end{array}$ & Gallons/minute $(\mathrm{g} / \mathrm{m})$ & 2.20 & 1.50 & 2.2 \\
\hline $\begin{array}{l}\text { Kitchen sink faucet, } \\
\text { duration } 15 \mathrm{~s}\end{array}$ & 02 & $\begin{array}{l}\text { Male } \\
\text { Female }\end{array}$ & $\begin{array}{l}1 \\
1\end{array}$ & $\mathrm{~g} / \mathrm{m}$ & 2.20 & 1.8 & 2.2 \\
\hline Bidet spray & 35 & $\begin{array}{l}\text { Male } \\
\text { Female }\end{array}$ & $\begin{array}{l}1 \\
3\end{array}$ & $(g / m)^{*}$ & 2.11 & 1.3 & 3.1 \\
\hline
\end{tabular}

Bidet spray (gpm)* value for bidet spray commonly called Muslim shower in Pakistan are taken from uniform plumbing codes of Abu Dhabi

Table 2 Equations to calculate water consumption for fixture type

\begin{tabular}{ll}
\hline Fixture type & Equations \\
\hline Water closet single flush & $W_{w c s f}=C_{f} \times\left(t_{n} \times O_{n}\right) D_{n} \times W C_{n}$ (Eq. 1) \\
Water closet dual flush & $W_{w c d f}=C_{f} \times\left(t_{n} \times O_{n}\right) D_{n} \times W C_{n}$ (Eq. 2) \\
Urinals & $W_{u}=C_{f} \times\left(t_{n} \times O_{n}\right) D_{n} \times U_{n}$ (Eq. 3) \\
Bidet spray & $W_{b s}=Q \times\left(t_{n} \times O_{n}\right) D_{n} \times B S_{n}$ (Eq. 4) \\
Lavatory faucets & $W_{l f}=Q \times\left(t_{n} \times O_{n}\right) D_{n} \times L F_{n}$ (Eq. 5) \\
Kitchen faucets & $W_{k f}=Q \times\left(t_{n} \times O_{n}\right) D_{n} \times K F_{n}$ (Eq. 6) \\
\hline
\end{tabular}

\subsection{Water consumption by means of plumbing fixtures}

Water consumption in the building has been computed considering the current number of the occupants and future maximum number of the occupant has been calculated by using equations given in Table 2 . The water consumption using single flush water closet and double flush water closet has been calculated using Eqs 1, 2 respectively for both genders. Equation 3 has been used for calculation of water consumption by the urinal. Equation 4 has been used for calculation of water consumption by bidet spray, for both genders. Equation 5 has been used for the calculation of water consumption by using lavatory faucet and Eq. 6 has been used for the calculation of water consumption by using kitchen faucet. The terminology used in these formulae are defined in the nomenclature given below.

\section{Results}

\subsection{Water consumption by fixture type}

\subsubsection{Water closet single flush (WCSF)}

Water consumption by WCSF in the building during 8 working hours has been calculated for both scenarios i.e. current occupancy and complete space occupancy by using Equ 1, for both genders separately. Same equation has been used for conventional and high-efficient water consumption methods only values are changed as per standards of conventional and high-efficient fixtures given in Table 1, results are calculated and plotted in Fig. 2a.

In scenario 1, where present number of occupants have been considered for analysis of water consumption. Therefore, results show in the Fig. $2 \mathrm{a}$ by WCSF-male, where $1667.82 \mathrm{~m}^{3}$ water is used in a month during working days considering 8 working hours by using water via conventional fixtures and, $512.82 \mathrm{~m}^{3}$ water is used by female occupants. On the other hand, highefficiency WCSF-male consume $1348.15 \mathrm{~m}^{3}$ water in a month during working hours and high-efficiency WCSFfemale consume $414.53 \mathrm{~m}^{3}$ water.

In scenario 2, where exceptional situation has been considered of maximum occupants present in the building. WCSF-male, via conventional fixtures consume $1455.30 \mathrm{~m}^{3}$ water in a month and female consume 

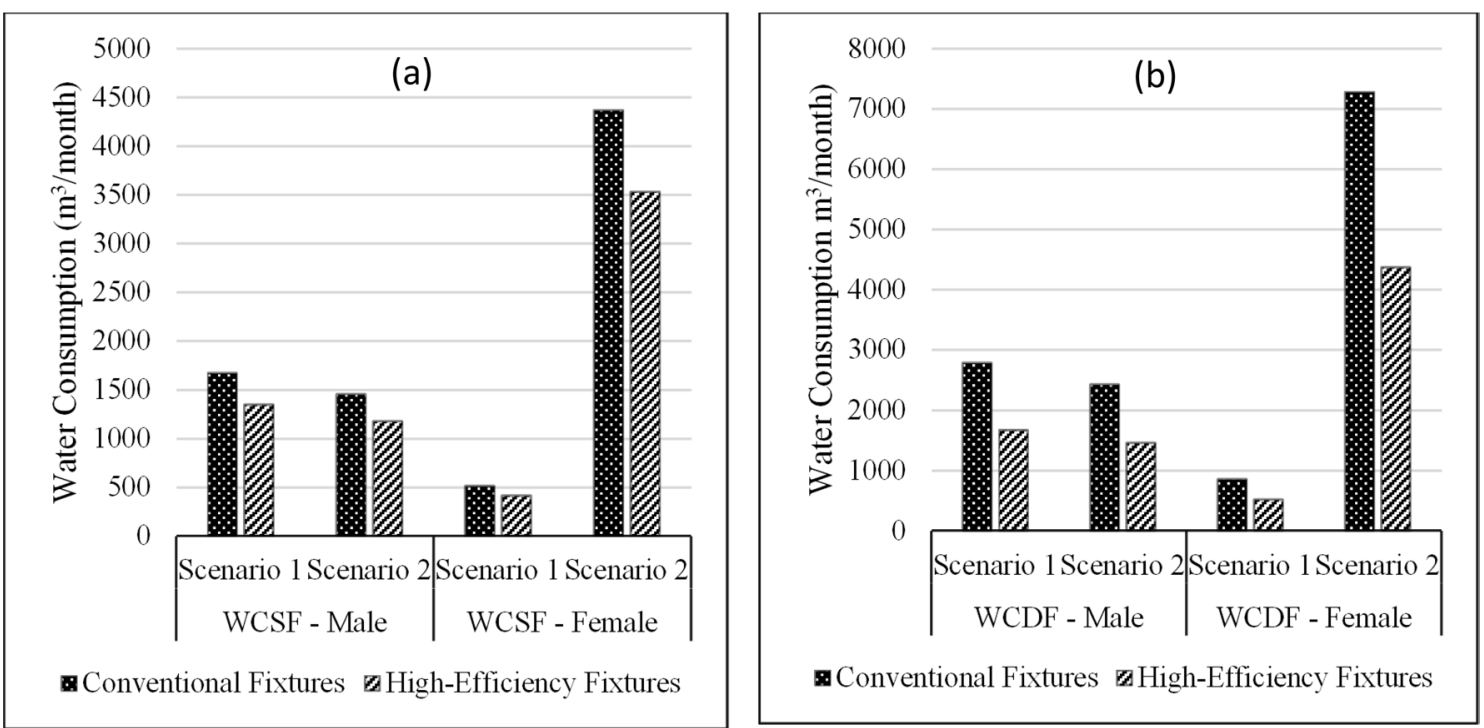

Fig. 2 Comparison of conventional and high-efficiency water closet for male and female occupant (a) single flush (b) dual flush

$4365.90 \mathrm{~m}^{3}$ water. Here same data have been used as per scenario 1, but only number of occupant's value has been replaced with maximum number. WCSF-male, by using high-efficiency fixture consume $1176.36 \mathrm{~m}^{3}$ water in a month and WCSF-female consume $3529.10 \mathrm{~m}^{3}$ water.

\subsubsection{Water closet dual flush (WCDF)}

Water consumption by WCDF in building during working hours has been calculated for both scenarios using Eq. 2. For scenario 1 results show in the Fig. 2b WCDF-male $2779.70 \mathrm{~m}^{3}$ water have been used in a month during working days via conventional fixtures and WCDF-female consume $854.70 \mathrm{~m}^{3}$ water. Results of water consumption by WCDF-male by using high-efficient fixtures. $1667.82 \mathrm{~m}^{3}$ water have been consumed in a month during working hours and water consumption through WCDF-female by using high-efficiency fixtures have been calculated $512.82 \mathrm{~m}^{3}$. In scenario 2, WCDF-male by conventional fixtures consume $2425.50 \mathrm{~m}^{3}$ water in a month and WCDF-female consume $7276.50 \mathrm{~m}^{3}$ water per month. WCDF-male, by using high-efficiency fixture consume $1455.30 \mathrm{~m}^{3}$ water in a month and WCDF-female, by using high-efficiency consume $4365.90 \mathrm{~m}^{3}$ water in a month.

\subsubsection{Urinal and bidet spray}

In scenario 1, where present number of occupants have been considered for analysis of water consumption. Therefore, results show, $480.33 \mathrm{~m}^{3}$ water is used by urinals in a month during working days by using conventional fixtures. On the other hand, high-efficiency urinals consume $240.16 \mathrm{~m}^{3}$ water in a month during working hours. In scenario 2, Urinal by conventional fixtures consume $419.13 \mathrm{~m}^{3}$ water in a month and by highefficiency urinals consume $209.56 \mathrm{~m}^{3}$ water.

For scenario 1, results show bidet spray, where $727 \mathrm{~m}^{3}$ water has been used in a month during working days via conventional fixtures. Whereas high-efficiency fixtures consume $454 \mathrm{~m}^{3}$ water per month. In scenario 2, bidet spray by conventional fixtures consume $1940 \mathrm{~m}^{3}$ water in a month and via high-efficiency fixtures consume $1212 \mathrm{~m}^{3}$ water in a month.

\subsubsection{Lavatory and kitchen faucet}

For scenario 1, results show, by lavatory faucet $2458.68 \mathrm{~m}^{3}$ water is used in a month during working days via conventional fixtures and $1666.70 \mathrm{~m}^{3}$ water is consumed via high-efficiency fixtures. In scenario 2 , lavatory faucets by conventional fixtures consume $3891.89 \mathrm{~m}^{3}$ water in a month and high-efficiency fixtures consume $2638.25 \mathrm{~m}^{3}$ water.

Kitchen faucet water consumption in scenario 1 is $36.42 \mathrm{~m}^{3}$ via conventional fixtures and $29.77 \mathrm{~m}^{3}$ via highefficient fixtures. On the other hand, in scenario 2, kitchen faucet consumes $57.56 \mathrm{~m}^{3}$ water via conventional fixture and $47.12 \mathrm{~m}^{3}$ via high-efficient fixtures.

\subsection{Total estimated water consumption in the institution/building}

The institutional building with above mentioned specifications analyzed based on occupant's fixture use 
rate during working days of a month i.e. approximately 22 days. Two scenarios were considered to calculate the total water consumption in the building.

Thus, the estimates are approximately $9517.32 \mathrm{~m}^{3}$ water have been consumed in a month in scenario 1 , by using conventional fixtures and approximately $6335.53 \mathrm{~m}^{3}$ water have been consumed in a month in scenario 1 by using high efficiency fixtures certified by U.S.EPA. Similarly, in scenario 2, amount of water consumed by occupants in a month by using conventional fixtures in the building is $21,832.27 \mathrm{~m}^{3}$, on the other hand amount of water consumed by occupants in a month through using certified fixtures given by U.S. EPA was $14,632 \mathrm{~m}^{3}$. In both scenarios more than half amount of freshwater consumption can be conserved if efficient fixtures are used in the building.

\section{Discussion}

\subsection{Fixture type}

Considering above results of scenario 1 , when high-efficient WCSF were used then, under current circumstance, the total potential saving of water is approximately $418 \mathrm{~m}^{3} /$ month. It is a reasonable amount of water which is sufficient for another 96 occupants if efficient fixtures will be installed with current proportion of male and female occupants. It is interesting to note in scenario 2, by using efficient WCSF and considering equal numbers of male and female occupant, the per capita potential saving of water is approximately about $1.77 \mathrm{~m}^{3} /$ month. By considering the same proportion of male and female occupants, the average per capita saving is approximately about $1.05 \mathrm{~m}^{3}$ of water, which indicate that $650 \mathrm{~m}^{3}$ can be saved at minimum while using efficient fixture.

Results show that, conventional WCDF consumes maximum water in the building. At the same time replacement with high-efficiency WCDF conserve water as shown in Fig. 2b. Considering both scenarios, water used in conventional flushing is about $13,335.7 \mathrm{~m}^{3} /$ month. Replacing conventional fixtures with highefficiency fixtures conserve $5334 \mathrm{~m}^{3} /$ month of water.

High-efficiency urinals consume less water when compared to conventional urinals results for both scenarios show almost half of the amount of water consumed via conventional fixtures can be saved which can be used for different purposes in the building. Conventional urinals consume $1 \mathrm{~L}$ water during single use whereas, urinals designed for sustainable design consume half litre of freshwater during single use as given in Table 1. Replacing conventional bidet spray with high-efficient bidet spray consume less water in both scenarios. Water consumption only via bidet spray consumes $2667 \mathrm{~m}^{3}$ water in both scenarios, while using efficient fixtures can save up to $1001 \mathrm{~m}^{3} /$ month. In Muslim countries bidet spray is specially provided in the toilet, as it is used every time while using toilet. Therefore, it is highly recommended to use high-efficient bidet sprays in the toilets to lower the freshwater burden.

Lavatory Faucets consume maximum water after water closets in the building. Using high-efficient lavatory faucets conserve water as calculated and shown in Fig. 3a. Introducing efficient fixtures can save about $792 \mathrm{~m}^{3}$ water every month in scenario 1 and
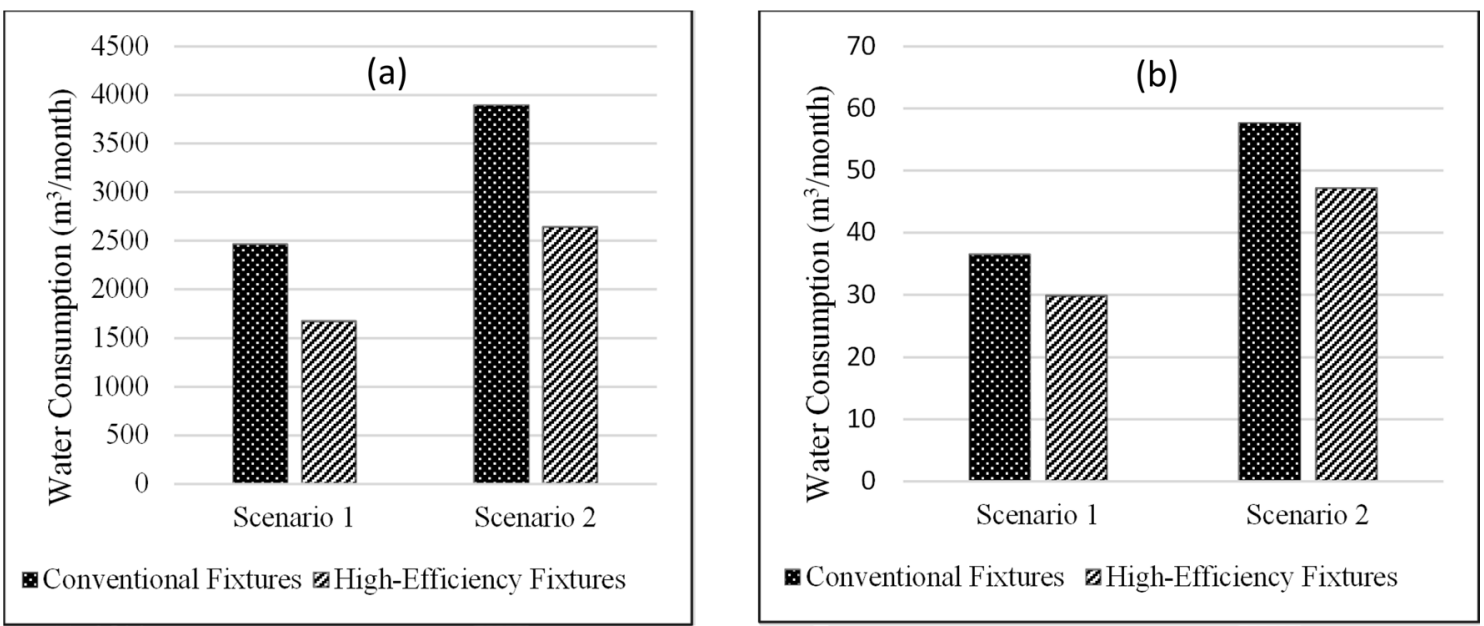

Fig. 3 Comparison of conventional and high-efficiency (a) lavatory faucet (b) kitchen faucet 

consumption by conventional and high-efficiency fixtures in scenario 1 and scenario 2
Table 3 Monthly water

\begin{tabular}{|c|c|c|c|c|c|}
\hline \multirow[t]{2}{*}{ Fixture Type } & \multirow[t]{2}{*}{ Gender } & \multicolumn{2}{|l|}{ Scenario 1} & \multicolumn{2}{|l|}{ Scenario 2} \\
\hline & & $\begin{array}{l}\text { Conventional } \\
\text { fixtures }\left(\mathrm{m}^{3}\right)\end{array}$ & $\begin{array}{l}\text { High-efficiency } \\
\text { fixtures }\left(\mathrm{m}^{3}\right)\end{array}$ & $\begin{array}{l}\text { Conventional } \\
\text { fixtures }\left(\mathrm{m}^{3}\right)\end{array}$ & $\begin{array}{l}\text { High-efficiency } \\
\text { fixtures }\left(\mathrm{m}^{3}\right)\end{array}$ \\
\hline \multirow[t]{2}{*}{ Water closet single flush } & Male & 1667.82 & 1348.15 & 1455.30 & 1176.36 \\
\hline & Female & 512.82 & 414.53 & 4365.90 & 3529.10 \\
\hline \multirow[t]{2}{*}{ Water closet dual flush } & Male & 2779.70 & 1667.82 & 2425.50 & 1455.30 \\
\hline & Female & 854.70 & 512.82 & 7276.50 & 4365.90 \\
\hline Urinals & Male & 480.33 & 241.43 & 419.13 & 210.67 \\
\hline \multirow[t]{2}{*}{ Bidet spray } & Male & 555.94 & 347.46 & 485.10 & 303.18 \\
\hline & Female & 170.95 & 106.84 & 1455.30 & 909.56 \\
\hline Lavatory faucets & Both & 2458.63 & 1666.70 & 3891.88 & 2638.25 \\
\hline Kitchen faucets & Both & 36.42 & 29.77 & 57.65 & 47.12 \\
\hline
\end{tabular}

approximately $1254 \mathrm{~m}^{3}$ water is scenario 2 . Kitchen faucets consume minimum amount of water in the building, as per the calculations done by considering occupant count for both scenarios. Still difference is seen in Fig. 3b. Where high-efficiency kitchen faucets consume less water when compared to conventional one.

\subsection{Water consumption by conventional and high-efficiency fixtures in scenario 1 and scenario 2}

Figure 3a and Table 3 gives a brief picture of water consumption by fixture type in scenario 1 . WCDF-male is the most water consuming fixture. Second is Lavatory Faucet the most water consuming fixture during working hours in an institutional building. WCSF-male is next in the list. Therefore, it shows that water closet is most water consuming fixture and grey water reuse can save water consumption. Effluent water discharging from Lavatory faucets can be used for flushing. Grey water reuse can reduce impacts of resource consumption. Input-output oriented Impacts can be reduced. Input oriented impacts in this case are freshwater use and output-oriented impacts are energy consumption and environmental degradation. Almost all public buildings are not using efficient fixtures. An awareness programs need to introduce. Water conservation will not only help to save water but also energy, which is being used for pumping, treatment and supplying of water.

Likewise, Fig. 4b and Table 3 shows complete picture of water consumption by fixture type in scenario 2. The most water consuming fixture in this case is WCDF-female. Water consumption by female occupant has been observed very high in scenario 2 than male
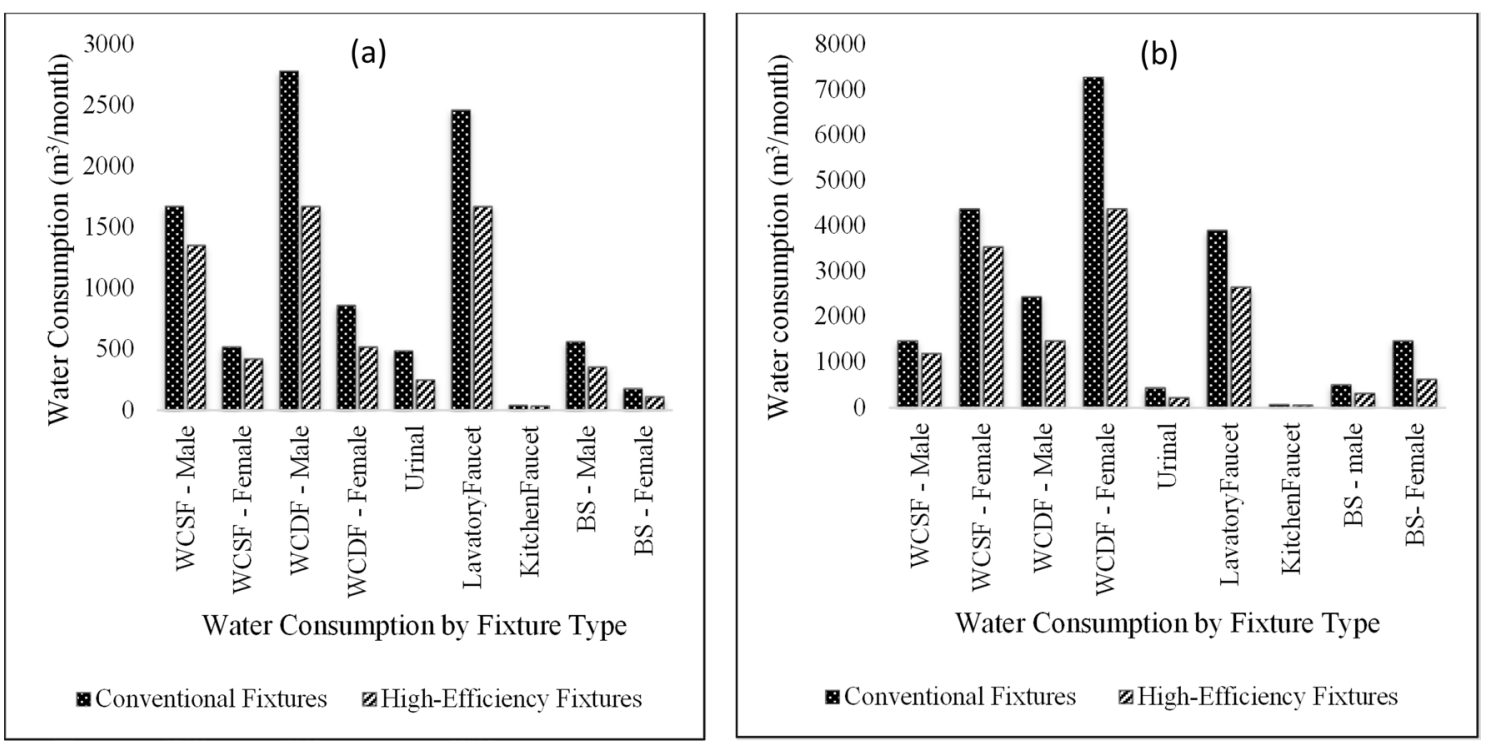

Fig. 4 Comparison of water consumption by fixture type a scenario1, b scenario2 
occupants, the reason behind is the number of female occupants in scenario 2 are assumed equal to male occupants as per the gender equality policy of center. Secondly, according to Table 1 female FTE is 3 times a day on the other hand male FTE is 1 time a day for water closet. Male occupants are using flush once a day and urinal twice a day. Therefore, water consumption via single and dual flush by female occupants increase drastically.

\subsection{Consumption of water for toilet flushing and lavatory faucets}

Study shows the joint results of both scenarios of freshwater consumption by conventional single and dual flush water closet (male and female) in the institutional building during working hours in a month. $5815 \mathrm{~m}^{3}$ water was consumed in scenario 1 and $15,523 \mathrm{~m}^{3}$ water was consumed in scenario 2 . Study shows the joint result of both scenarios of freshwater consumption via lavatory faucets (male and female) in the building for 1 month. $2458.63 \mathrm{~m}^{3}$ water was consumed in scenario 1 and $3891.88 \mathrm{~m}^{3}$ water was consumed in scenario 2. With respect to this, reuse of faucet water in toilet flushing can be done to save freshwater consumption in the institute.

\subsection{Water conservation strategies/measures to reduce water consumption}

\subsubsection{Use of high-efficient fixtures}

Results of estimated water consumption in building shows that $9517.32 \mathrm{~m}^{3}$ water have been consumed in a month in scenario 1 , by using conventional fixtures and $6335.53 \mathrm{~m}^{3}$ water have been consumed in a month in scenario 1 by using high efficiency fixtures certified by U.S.EPA. This shows that $33 \%$ of fresh water is conserved due to replacement of fixtures in the building. As shown in Fig. 4.

Similarly, in scenario 2, amount of water consumed by occupants in a month thru using conventional fixtures in the building is $21,832.27 \mathrm{~m}^{3}$, on the other hand amount of water consumed by occupants in a month through using certified fixtures given by U.S. EPA conserve $34 \%$ of fresh water by replacing fixtures with efficient fixtures as shown in Fig. 5.

\subsubsection{Reuse of grey water}

It has been observed from above calculations that maximum water consumption during working hours in an institute takes place by conventional water closets. On

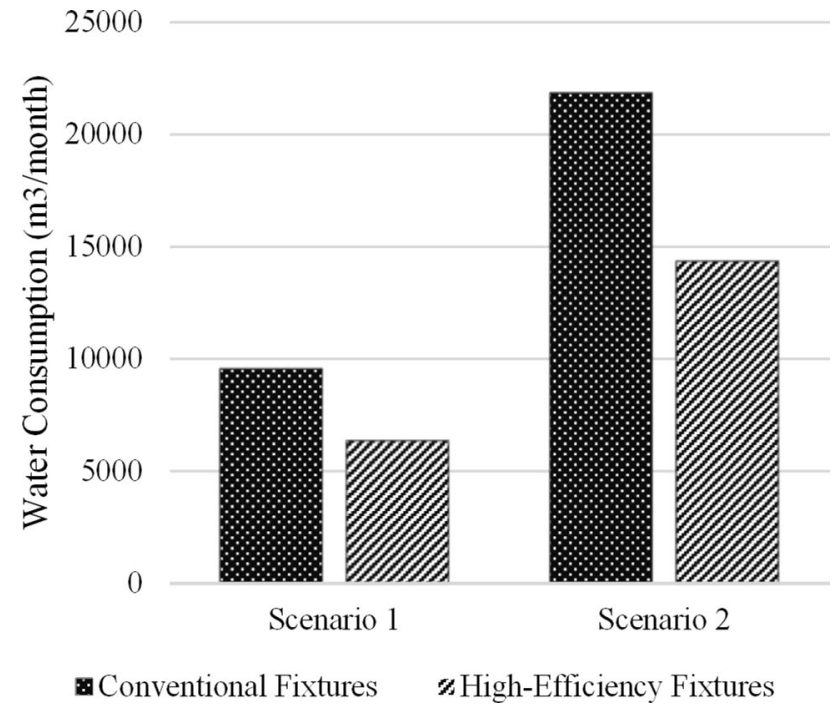

Fig. 5 Comparison of conventional and high-efficiency fixtures in scenario 1 and scenario 2

other hand, it has been also observed that, second most water consuming fixture was lavatory faucet. In public and institutional buildings, the possibility of installing highefficient fixtures is more. This would save water as well as energy used for pumping the water. Purchase of modern water saving fixtures may become difficult therefore, in this study another possibility of fresh water saving via grey water reuse has been analyzed.

Results shows water consumed via single and dual flush water closet can be saved by grey water reuse. Grey water coming from lavatory faucets can be saved and reused in the water closet flush. The results show that, in scenario $1,42 \%$ freshwater consumption via water closet flush can be conserved by using grey water. In scenario 2, 25\% fresh water can be saved during use of single and dual flush water closet when grey water has been used for flushing. Adoption of proposed saving measures can conserve large amount of fresh water used in the institutional buildings for everyday use. Therefore, this would be the great contribution of water resources preservation for future generations. To balance the pressures of water supply and the increasingly stringent nutrient discharge standards for WWTFs, there is a need to better understand the impacts of water conservation and reuse strategies on WWTF operations and receiving water body quality. To stable water supply pressure and the increasingly sever demand of fresh water in academic buildings, there is a necessity to understand the positive influences of water conservation and reuse [27]. 


\section{Conclusions}

High-efficiency measures are needed in the academic buildings. As the academic buildings consume large amount of fresh water during building operation. In this study, an attempt is made to reduce the water consumption by occupants during working hours. For this purpose, two scenarios based on occupant count were developed for the case study academic building. Indoor water fixtures were replaced with high-efficiency fixtures. Calculations carried out according to measures given by LEED reference guide. Results shows that during scenario 1 high-efficiency fixtures conserve 33\% water and for scenario 2 high-efficiency fixtures conserve $34 \%$ water as compared to conventional fixtures. In new buildings, these measures can be applied easily. Moreover, results are analyzed for grey water reuse. During scenario 1 using gray water instead of fresh water in single and dual flush can conserve $42 \%$ fresh water in flushing, similarly in scenario 2, 25\% freshwater use via flushing can be saved by using gray water coming from lavatory faucets. The study can be helpful in providing water efficient measures in the pre-design stage of building construction to obtain the expected results. This study not only aim to save water resources but also ensure to reduce the environmental impacts. These are the techniques of green building which are being used globally. Pakistan is also working on green building labelling; green guidelines are published in October 2016 by Pakistan Green Building Council. Country like Pakistan with limited resources and high density of population, the green building techniques are important and signifies helpful pace toward sustainable development and environmental well-being. This is the soul responsibility of construction sector in which planning, and development sector also includes, they must come up with sustainable solutions for betterment of water consumption in post and pre operation phase of building. Building laws must be introduced where every new construction owner is advised to indicate provision of water conservation measures and this should be taken place at the design phase. Looking at the way forward of this study, there are several options for researchers to explore the water conservation measures in institutes by observing end user behavior or willingness of users to limit the maximum water consumption in the building can be assessed. In the context of Pakistan there are way too many options to analyze the different scenarios in major and minor cities and public and private sector institutes in different cities.
Acknowledgements The authors are thankful to U.S.-Pakistan Center for Advanced Studies in water (USPCAS-W), USAID, University of Utah, Architecture and Chemical Engineering Department of Dawood University of Engineering and technology, Karachi. Authors are thankful to Eng. Abdul Maroof Lashari and Eng. Sajjad Qureshi for landing helping hand in study.

Author contributions This work was performed for the fulfilment of master's degree requirement of Bushra Danish Talpur. Dr. Asmatullah supervised the work and Shoaib Ahmed contributed to the data analysis.

Funding This study was conducted at U.S. Pakistan Center for Advanced Studies in Water, Mehran UET, Jamshoro, Sindh, Pakistan and funded by USAID.

\section{Compliance with ethical standards}

Conflict of interest Authors declare that they have no conflict of interest

\section{References}

1. Ahmed A, Iftikhar $\mathrm{H}$, Chaudhry GM (2007) Water resources and conservation strategy of Pakistan. Pak Dev Rev 46(4):997-1009

2. Aslam A, Tariq S, Syed WAA, Ali SS (2012) Green architecture and environmental benefits: a review with reference to energy deficient Pakistan. Sci Int 24(4):495-498

3. Asian Development Bank, (2010) ADB Annual Report 2010, Manila, Philippines

4. GOP, National water policy. (2018) Government of Pakistan, Ministry of Water Resources. Islamabad, Pakistan, https:// mowr.gov.pk/index.php/national-water-policy-2018/

5. Bhatti AM, Nasu S (2010) Domestic water demand forecasting and management under changing socio-economic scenario. Soc Soc Manag Syst. http://ssms.jp/img/files/2019/04/sms 10 _183.pdf

6. Parry J-E, Osman H, Terton A, Asad SA, Ahmed T (2016) The vulnerability of Pakistan's water sector to the impacts of climate change: identification of gaps and recommendations for action. Int Inst Sustain Dev

7. Khoso S, Wagan FH, Tunio AH, Ansari AA (2015) An overview on emerging water scarcity in Pakistan, its causes, impacts and remedial measures. J Appl Eng Sci 13(1):35-44

8. Cheng C-L (2003) Evaluating water conservation measures for Green Building in Taiwan. Build Environ 38:369-379

9. Nunes LGCF, Soares AEP, Da Silva JK, Da Silva SR (2019) Rational water use indicators for public schools in Recife, Brazil. Water Sci Technol Water Supply 19(1):207-215

10. Munawir R (2014) Green buildings the cheapest way to slow global warming. Spat Econ 1-6

11. Berardi U (2012) Sustainability assessment in the construction sector: rating systems and rated buildings. Sust Dev 424:411-424

12. W P. Network, (2003) White paper on sustainability a report on the green building movement, Pittsburg: USA www.bdcma g.com

13. Yudelson J (2008) The green building revolution. Elsevier, USA

14. USGBC, (2009) LEED reference guide for green building design and construction 
15. Adeyeye K (2014) Water efficiency in buildings: theory and practice. John, Oxford

16. UN GA (2015) Transforming our world: the 2030 agenda for sustainable development. Division for sustainable development goals, New York

17. Marinho M, Gonçalves MDS, Kiperstok A (2014) Water conservation as a tool to support sustainable practices in a Brazilian public university. J Clean Prod 62:98-106

18. Mourad KA, Berndtsson JC, Berndtsson R (2011) Potential fresh water saving using greywater in toilet flushing in Syria. J Environ Manage 92(10):2447-2453

19. Proença LC, Ghisi E (2010) Water end-uses in Brazilian office buildings. Resour Conserv Recycl 54(8):489-500

20. Kim RH, Lee S, Jeong J, Lee JH, Kim YK (2007) Reuse of greywater and rainwater using fiber filter media and metal membrane. Desalination 202(1-3):326-332

21. Friedler E, Hadari M (2006) Economic feasibility of on-site greywater reuse in multi-storey buildings. Desalination 190(1-3):221-234

22. Bradley RM (2004) Forecasting domestic water use in rapidly urbanizing areas in Asia. J Environ Eng 130(4):465-471

23. Morales MA, Heaney JP, Friedman KR, Martin JM (2011) Estimating commercial, industrial, and institutional water use on the basis of heated building area. J Am Water Works Assoc 103(6):84-96
24. Kammers PC, Ghisi E (2006) Usos finais de água em edifícios públicos localizados em Florianópolis, SC. Ambient Construído 6(1):75-90

25. M. Ilha (2008) Programa de conservação de água em hospitais: Estudo de caso do Hospital das Clínicas da Universidade Estadual de

26. Epa U, WaterSense at work: best management practices for commercial and institutional facilities (2012) Denver. Colorado, USA

27. Hodgson B, Sharvelle S, Silverstein JA, McKenna A (2018) Impact of water conservation and reuse on water systems and receiving water body quality. Environ Eng Sci 35(6):545-559

28. Ilha MSO, Nunes SS, Pedroso LP, Arujo L, Oliveira OB Water conservation at the state university of Campinas. In: The international council for innovation and research in building and construction (CIB) 18-19 September 2002 Romania

29. Ghisi E, Rupp RF, Triska Y (2014) Comparing indicators to rank strategies to save potable water in buildings. Resour Conserv Recycl 87:137-144

30. Barberán R, Egea P, Gracia-de-Rentería P, Salvador M (2013) Evaluation of water saving measures in hotels: a Spanish case study. Int J Hosp Manag 34(1):181-191

31. Kalbusch A, Ghisi E (2016) Comparative life-cycle assessment of ordinary and water-saving taps. J Clean Prod 112:4585-4593

Publisher's Note Springer Nature remains neutral with regard to jurisdictional claims in published maps and institutional affiliations. 